\title{
Corrosion of Heat Treated Electroless-Ni Plated Mild Carbon Steels in Dilute $\mathrm{H}_{2} \mathrm{SO}_{4}$
}

\author{
Olawale Olarewaju Ajibola ${ }^{1,2, *}$, Abdullahi O. Adebayo ${ }^{2}$, Daniel Toyin Oloruntoba ${ }^{1}$ \\ ${ }^{1}$ Department of Metallurgical and Materials Engineering, Federal University of Technology, Akure, Nigeria \\ ${ }^{2}$ Department of Materials and Metallurgical Engineering, Federal University Oye Ekiti, Oye Ekiti, Nigeria
}

\section{Email address:}

olawale.ajibola@fuoye.edu.ng (O. O. Ajibola), abdullahi.adebayo@fuoye.edu.ng (A. O. Adebayo), dtoloruntoba@futa.edu.ng (D. T. Oloruntoba)

\section{To cite this article:}

Olawale Olarewaju Ajibola, Abdullahi O. Adebayo, Daniel Toyin Oloruntoba. Corrosion of Heat Treated Electroless-Ni Plated Mild Carbon Steels in Dilute $\mathrm{H}_{2} \mathrm{SO}_{4}$. International Journal of Materials Science and Applications. Vol. 4, No. 5, 2015, pp. 333-342. doi: 10.11648/j.ijmsa.20150405.18

\begin{abstract}
The corrosion of heat-treated Electroless-Nickel (EN) plated mild carbon steel (MCS) in dilute $\mathrm{H}_{2} \mathrm{SO}_{4}$ is investigated and reported in the study. The MCS samples were electroless-Ni plated in alkaline Nimudeen 850. EN plated samples were soaked at different selected temperatures between $150-370{ }^{\circ} \mathrm{C}$ at constant time. The weight loss of the specimens by full immersion method was employed to assess the corrosion damage and corrosion rates of the as-received, EN plated MCS and four heat treated EN plated samples in the $0.5 \mathrm{M} \mathrm{H}_{2} \mathrm{SO}_{4}$ solution. The test specimens were regularly examined at every $12 \mathrm{hrs}$ interval for 30 days $(720 \mathrm{hrs})$. The materials corrodes in $0.5 \mathrm{M} \mathrm{H}_{2} \mathrm{SO}_{4}$ in the order of MCS10 $>$ MCS14 > MCS15 > MCS11 > MCS13 > MCS12. Based on the results obtained, it will be justified to choose EN-plated samples (MCS 11) and the heat treated EN film (MCS12 and MCS13) for the purposed of solving the problem of corrosion in the medium. This is because; the application of EN deposition reduced the corrosion of MCS at much lower rate than the heat-treated EN film (MCS14 and MCS15) in $0.5 \mathrm{M} \mathrm{H}_{2} \mathrm{SO}_{4}$ environment. Atomic Absorption Spectrometer (AAS) Thermo series 2000 model and Scanning Electron Microscopy (SEM) with the Energy Dispersive X-Ray (EDX) facilities (Jeol JSM-7600F model) were used to ascertain the chemical compositions and the microstructures of samples.
\end{abstract}

Keywords: Corrosion, Heat Treatment, Electroless-Ni Plating, Mild Carbon Steel, Protective EN Film

\section{Introduction}

Several structural alloys including steels corrode simply from contact with moisture in the air, but the process can be strongly affected by interacting with certain acidic, neutral or alkaline substances. Protective film could be obtained with proper pre-treatment cycles and correct process control, good adhesion and brilliant service performance, very homogeneous thickness all over the component shape and size. Coating a surface with a thin film modifies the material surface characteristics, and it is a significant tool for controlling friction and wear at the surface [1]. Electroless nickel (EN) plating is a process of depositing a nickel alloy from aqueous solutions onto a substrate without the use of electric current. This is contrary to electroplating which relies on external source of direct current to reduce nickel ions in the conducting electrolyte to nickel metal on the substrate [2, $3,4]$. EN plating is an auto-catalytic chemical reduction process by which nickel ions is reduced to nickel metal in solution such as in sodium hypophosphite. It is used to deposit nickel-phosphorus or nickel-boron alloy on metal or plastic substrates $[5,6]$. The process is based on the presence of a reducing agent (usually hydrated sodium hypophosphite $\left.\left(\mathrm{NaPO}_{2} \mathrm{H}_{2} \cdot \mathrm{H}_{2} \mathrm{O}\right)\right)$ which reacts with the metal ions to deposit metal (Ni) $[7,8]$

$\mathrm{EN}$ is often a requisite to offer corrosion fortification and wear resistance. Heat treatment is frequently used to enhance the surface wear resistance properties [9] for their high hardness and good, natural lubrication characteristics $[2,10]$. EN deposits have low ductility and phosphorus content (\%) within the regular operating range has very little effect. EN deposits are hard and brittle film. The customary heattreatment measure for EN increases the hardness and reduces ductility, and thus wear resistance can be improved by heat treatment [11].

The corrosion resistant property of EN makes it very useful as a protective coating, though all EN deposits do not 
behave the same way $[12,13,14]$. High phosphorus deposits are comparatively substandard to low phosphorus deposits in high temperature and strongly alkaline media but are more efficient in neutral or acidic media. EN does not serve as a sacrificial coating in the same manner as zinc or cadmium does on steel substrates to provide protection against corrosion. It acts as a barrier coating between the corrosive media and the substrate. Thus, the film thickness and the absence of pores in the deposit are of great significance [2, 8 , $15,16]$.

EN has exceptional corrosion resistance and it is not vulnerable to stress corrosion cracking and can be deposited with a variety of composition for use in acidic, neutral or alkaline environments $[17,18]$. It is known that the surface finish of the substrate can appreciably influence the protective value of EN deposits; while smoother substrate surfaces give better quality electroless deposits [2]. Surface deficiencies often results from mechanical surface treatments and fabrication procedures such as rolling, stamping, drawing, shearing, lapping, machining, grit blasting and casting [19, 20].

Protective EN films (heat treated) with good adhesion [21] and homogeneous thickness often comes with distinct advantages when plating valves or threaded parts, holes, recesses, irregularly shaped objects and internal surfaces [8, 22].

Due to the hazardous nature of some metal coating processes such as the cadmium plating; alternate materials have been sought for many years by the manufacturing industries around the world. With respect to this, the corrosion of $\mathrm{Zn}-\mathrm{Ni}$, Ni-P, and $\mathrm{Ni}-\mathrm{B}$ deposits and the appraisal of their prospect as an alternative to cadmium have been extensively studied using different approach [23].

Several structural alloys including steels corrode simply from contact with moisture in the air, but the process can be strongly affected by contact with certain acidic, neutral, basic or alkaline substances [24]. Numerous studies have been carried out on the corrosion of mild carbon steels in various media such as $\mathrm{HCl}, \mathrm{H}_{2} \mathrm{SO}_{4}, \mathrm{NaOH}$ and $\mathrm{NaCl}$ [25]. Reports are also available on investigation of some control measures such as the application of electroplating [3,4,26]; galvanising; chemical vapour deposition (CVD) and plasma vapour deposition (PVD) [27, 28]. Hence the corrosion of heat treated EN plated MCS in dilute $\mathrm{H}_{2} \mathrm{SO}_{4}$ is investigated and reported in the present study.

\section{Methodology}

\subsection{Materials and Sources}

$300 \mathrm{~cm}$ length of $25 \mathrm{~mm}$ diameter mild carbon steel (MCS) rod samples and plating chemicals were collected from the Rolling mill Section of the Ajaokuta Steel complex, Kogi state, Nigeria. The plating chemicals including Nimudeen $850^{\circledR}$, Replenisher I and Standard grade of $\mathrm{H}_{2} \mathrm{SO}_{4}$ were obtained from the Nigeria Machine Tools NMT, Osogbo, Nigeria. The Chemical compositions of MCS samples are presented in Table 1.

Table 1. Chemical composition of MCS samples.

\begin{tabular}{|c|c|c|c|c|c|c|c|c|c|}
\hline Sample & $\% \mathrm{Si}$ & $\% M n$ & $\% \mathrm{P}$ & $\% \mathrm{~S}$ & $\% \mathrm{Cu}$ & $\% \mathrm{C}$ & $\% \mathrm{Fe}$ & C.E & UTS (N/mm2) \\
\hline MCS-10 & 0.182 & 0.747 & 0.0094 & 0.015 & 0.203 & 0.351 & 98.493 & 0.516 & 631 \\
\hline
\end{tabular}

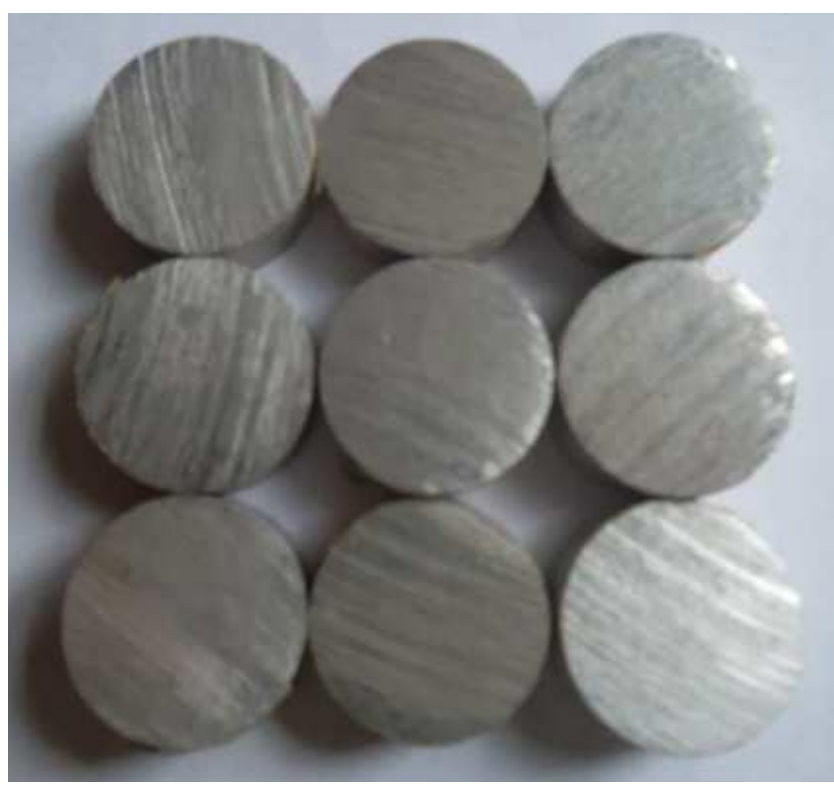

Fig. 1. The pictorial view of mild carbon steel samples used for the tests.

\subsection{Preparation of Samples}

The as-received mild carbon steel rod samples were cut to
$1.5 \mathrm{~cm}$ thickness and were polished using different grades of carbide paper grits which include $60 \mu \mathrm{m}, 120 \mu \mathrm{m}, 220 \mu \mathrm{m}$, $320 \mu \mathrm{m}, 400 \mu \mathrm{m}$ and $600 \mu \mathrm{m}$ on the grinding and polishing machines. The specimens were thoroughly cleaned and rinsed in water at room temperature for 1 minute. The initial weight $\mathrm{W}_{\mathrm{i}}$ was determined using a digital weighing machine. It was thereafter immersed for 1 minute in the emulsifier containing a mixture of Kerosene and Detergent solution necessary for the removal of soils (oil and grease stains) at operating temperature between $55-65{ }^{\circ} \mathrm{C}$. This was followed by alkaline cleaning and acid cleaning using $0.4 \mathrm{~g} / 1 \mathrm{NaOH}$ and $0.01 \mathrm{M} \mathrm{HCl}$ solutions respectively operating between $60-70{ }^{\circ} \mathrm{C}$ for 1 minute. The surface of the specimen was activated by dipping in surfactant bath made of palladium chloride $\mathrm{PdCl}_{2}$ solution $(0.04 \mathrm{~g} / \mathrm{l})$ at $85^{\circ} \mathrm{C}$ for 20 seconds. The specimen is rinsed from time to time in water at room temperature.

The pre-cleaned sample was submerged in EN plating bath (of alkaline reduced EN plating solution) for 10 mins. The EN plating bath consists of ratio 1 to 4 of Nimudeen $850^{\circledR}$ to distilled water, and $3.5 \mathrm{~g} / 1$ of Replenisher $I^{\circledR}$ with $5 \mathrm{~g} / 1 \mathrm{H}_{2} \mathrm{SO}_{4}$. The EN plating temperatures were varied as 80,85 and $90^{\circ} \mathrm{C}$. The EN plated sample was removed from the EN plating tank, rinsed in water and immersed in anti-tarnish chemical 
consisting $5 \mathrm{~g} / 1$ potassium-di-chromate solution at temperature range between 50 and $65^{\circ} \mathrm{C}$ for about 20 seconds. The EN plated samples were dried in oven and kept in the desiccators before the final weight $\mathrm{W}_{\mathrm{f}}$ is determined using a digital weighing machine (model DT-502A, $0.0001 \mathrm{~g}$ ).

The amount of EN deposit $\left(\Delta \mathrm{W}_{\mathrm{p}}\right)$ on the MCS substrate is determined from the difference between the initial weight $\left(\mathrm{W}_{\mathrm{pi}}\right)$ and the final weight $\left(\mathrm{W}_{\mathrm{pf}}\right)$ before and after immersion plating respectively. The difference is mathematically expressed as in (1):

$$
\Delta \mathrm{W}_{\mathrm{p}}=\mathrm{W}_{\mathrm{pf}}-\mathrm{W}_{\mathrm{pi}}
$$

where $\mathrm{W}_{\mathrm{pi}}=$ initial weight of the sample before EN plating.

$$
\mathrm{W}_{\mathrm{pf}}=\text { final weight of the sample after EN plating. }
$$

The amount deposited per unit area was calculated from the amount deposited as the ratio of electroless-nickel film weight deposited to the total surface area of plated sample [3].

\subsection{Heat Treatment of EN Plated Mild Carbon Steel Samples}

EN plated samples (MCS12, MCS13, MCS14 and MCS15) were placed in the heat treatment furnace and fired at different selected soaking temperatures and constant time as presented in Table 2.

Table 2. Heat treatment of EN plated mild carbon steel samples.

\begin{tabular}{llll}
\hline Sample No & Treatment Description & $\begin{array}{l}\text { Soaking } \\
\text { Temp. }\left({ }^{\circ} \mathrm{C}\right)\end{array}$ & $\begin{array}{l}\text { Soaking } \\
\text { time (min) }\end{array}$ \\
\hline MCCS10 & Not plated, Not heat treated & - & - \\
MCS11 & Plated, Not heat treated & - & - \\
MCS12 & Plated, Heat treated & 150 & 60 \\
MCS13 & Plated, Heat treated & 210 & 60 \\
MCS14 & Plated, Heat treated & 250 & 60 \\
MCS15 & Plated, Heat treated & 370 & 60 \\
\hline
\end{tabular}

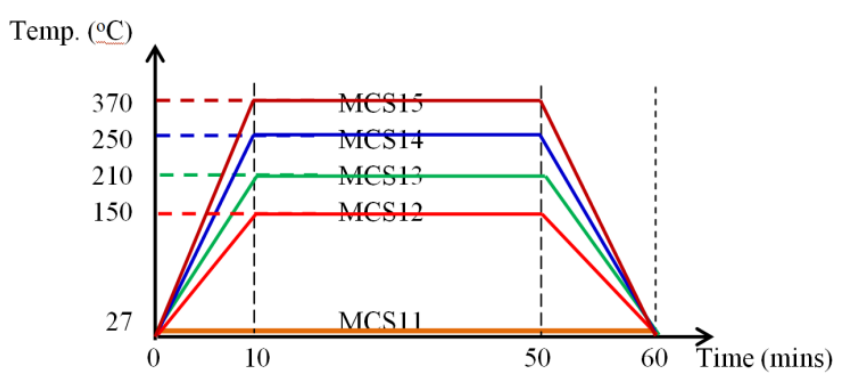

Fig. 2. Heat treatment cycle used for the experiment.

\subsection{Determination of Corrosion Rates of Heat Treated EN Plated MCS Samples in $0.5 \mathrm{M} \mathrm{H}_{2} \mathrm{SO}_{4}$}

The weight loss of specimen by full immersion method was employed to assess the corrosion damage and corrosion rates of the as-received and EN plated MCS samples in the $0.5 \mathrm{M} \mathrm{H}_{2} \mathrm{SO}_{4}$ solution. The initial weights $\left(\mathrm{M}_{1}\right)$ of the samples were measured immediately after the surface cleaning using an electric digital weighing machine measure to $0.0001 \mathrm{~g}$. Samples were fully immersed in plastic vessels containing $25 \mathrm{~cm}^{3}$ of the test media $\left(0.5 \mathrm{M} \mathrm{H}_{2} \mathrm{SO}_{4}\right)$.
After each immersion time, the specimens were removed, rinsed in water and dried with cotton wool to remove water and other impurities before the final weights $\left(\mathrm{M}_{2}\right)$ were determined. The chemical corrosion weight loss was calculated form the difference between the initial weight $\left(\mathrm{M}_{1}\right)$ and initial weight $\left(\mathrm{M}_{2}\right)$ of the specimen before and after immersion respectively. The as-received and EN plated MCS specimens were regularly examined at every $12 \mathrm{hrs}$ for 30 days $(720 \mathrm{hrs})$. The same experimental procedure was carried out repeatedly on the EN plated the MCS samples.

The corrosion rate was calculated in mils per year using Equation 2 according to ASTM as reported by Fontana [29], Oloruntoba [30]; and Ajibola and Oloruntoba [3].

$$
\text { Corrosion Rate }(\mathrm{R})=\left(\mathrm{K} \Delta \mathrm{W}_{\mathrm{c}}\right) /(\rho \mathrm{At})
$$

where Weight loss to corrosion $\Delta \mathrm{W}_{\mathrm{c}}(\mathrm{g})=\mathrm{W}_{\mathrm{ci}}-\mathrm{W}_{\mathrm{cf}}=\left(\mathrm{M}_{1}-\right.$ $\left.\mathrm{M}_{2}\right)(3)$

$\mathrm{W}_{\mathrm{ci}}=$ Initial weight $\left(\mathrm{M}_{1}\right)$ of the sample before corrosion test.

$\mathrm{W}_{\mathrm{cf}}=$ Final weight $\left(\mathrm{M}_{2}\right)$ of the sample after corrosion test.

$\rho=$ Density of the material

$\mathrm{A}=$ Total area of exposure

$\mathrm{t}=$ Exposure time

$\mathrm{K}=534$ (Corrosion rate constant)

The corrosion impact on the appearance, colour and roughness of substrate surfaces were also examined.

\subsection{Metallurgical Studies on MCS Substrates and EN Plated Samples}

The chemical characterisation and micrography were used to understudy the metallurgical properties such as chemical composition, roughness and microstructures of the substrate specimens (as-received and EN plated MCS samples). The chemical analyses were performed using Atomic Absorption Spectrometer (AAS) Thermo series 2000 model. The physical quality such as the brightness, appearance, colour and roughness of EN depositions were studied using high resolution microscopic camera (Samsung ST65/HD5X-14.2 model). The EN film deposition was characterised by Scanning Electron Microscopy and Energy Dispersive X-Ray analyses using Jeol JSM-7600F Field Emission SEM/EDX. The SEM photo-micrographs and EDX spectra lines data produced were used to discuss the results.

\section{Results and Discussion}

\subsection{Determination of Electroless-Nickel Plating Parameters on Steel Substrates}

The effect of the heat treatment on the morphologies (appearance, adhesion and micro-structures) and corrosion of EN deposition on MCS substrates were examined. Figs. 3-5 compare the different surfaces of the specimens. The Fig. 3a 
shows the appearances of the as-received sample (MCS10) prior to its chemical cleaning and (b) the EN plated but not heat-treated sample (MCS11) which is characterised with uniform layer of the rich electroless-nickel film.

The effects of heat-treatment on the surface appearances (lustre) of EN plated MCS(12-15) samples baked at 150$370{ }^{\circ} \mathrm{C}$ soaking temperatures are shown in Fig. 4(a-d). The chemical characterisation as revealed by EDX spectral data (Table 3,) shows that the targeted area of the SEM in Fig. 5a consists of very rich nickel-phosphorus film, laid over the chromate activated MCS sample. The corresponding EDX data (Table 3) reports about $60.34 \% \mathrm{Ni}$ and $10.57 \% \mathrm{P}$ for the 10 mins of EN plating on chromate activated MCS substrate. Under similar SEM/EDX observation; the black portions of the Ni-P rich EN deposition shows that the 100 um size SEM electron image (Fig. 5b and Table 4) of EN plating contains $11.94 \% \mathrm{P}$, and $51.78 \% \mathrm{Ni}$ with traces of $0.52 \% \mathrm{Zn}$ and substantial amounts of $1.11 \% \mathrm{Pd}$, being deposited from the zincate and $\mathrm{PdCl}_{2}$ activated solutions respectively (Table 4). This shows that the EN film is more of the Ni-P film than the metallic Ni deposition than as it is obtainable in the electroplating process [30].

Table 3. EDX Spectrum processing data for 10 mins of EN plating on chromate activated MCS sample.

\begin{tabular}{|c|c|c|c|c|c|c|c|c|c|c|c|}
\hline Element & $\mathrm{C}$ & $\mathbf{O}$ & $\mathbf{N a}$ & $\mathbf{F e}$ & Si & Mn & $\mathrm{Cu}$ & $\mathbf{P}$ & $\mathrm{Cr}$ & $\mathbf{N i}$ & Total \\
\hline Weight $\%$ & 3.36 & 4.35 & 2.11 & 7.34 & 3.67 & 3.69 & 2.26 & 10.57 & 1.31 & 60.34 & 100 \\
\hline
\end{tabular}

Table 4. EDX Spectrum processing data of Ni-P rich EN deposition on MCS substrate.

\begin{tabular}{|c|c|c|c|c|c|c|c|c|c|c|c|c|c|}
\hline Element & $\mathrm{C}$ & O & $\mathrm{Na}$ & $\mathbf{S i}$ & $\mathbf{P}$ & $\mathrm{Fe}$ & Cl & $\mathbf{N i}$ & Mn & $\mathrm{Cu}$ & $\mathrm{Zn}$ & Pd & Total \\
\hline Wt \% & 7.21 & 6.88 & 0.85 & 6.11 & 11.94 & 6.24 & 0.91 & 51.78 & 3.51 & 2.85 & 0.52 & 1.11 & 100 \\
\hline
\end{tabular}
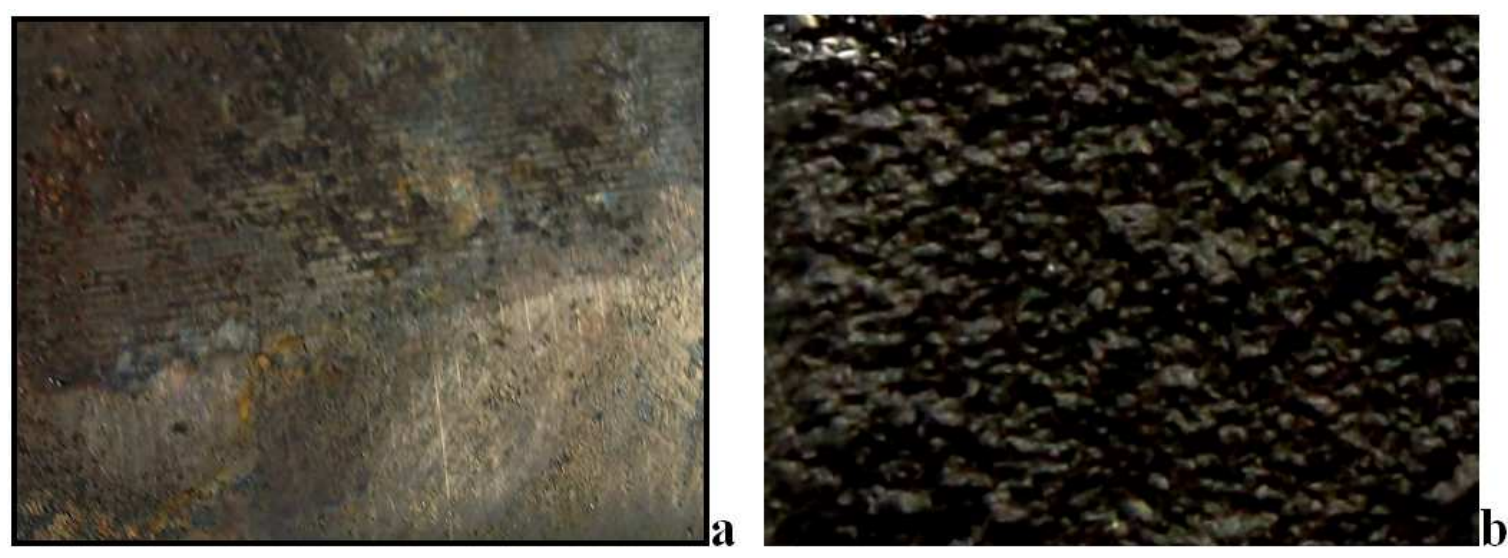

Fig. 3. Showing (a) As-received sample (MCS10) and (b) EN plated, not heat-treated sample (MCS11) (x50 mag.).
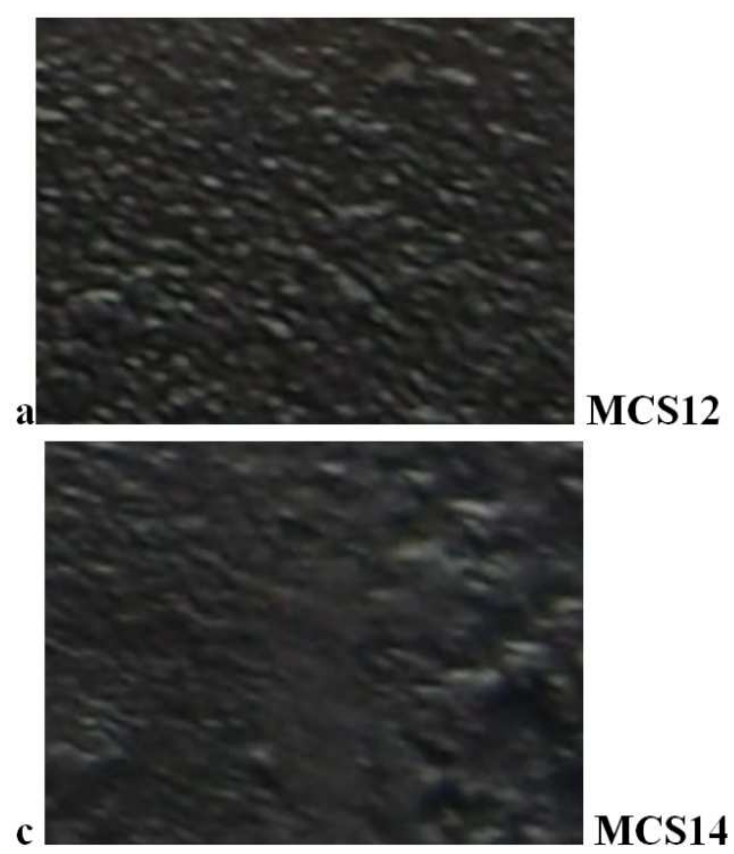

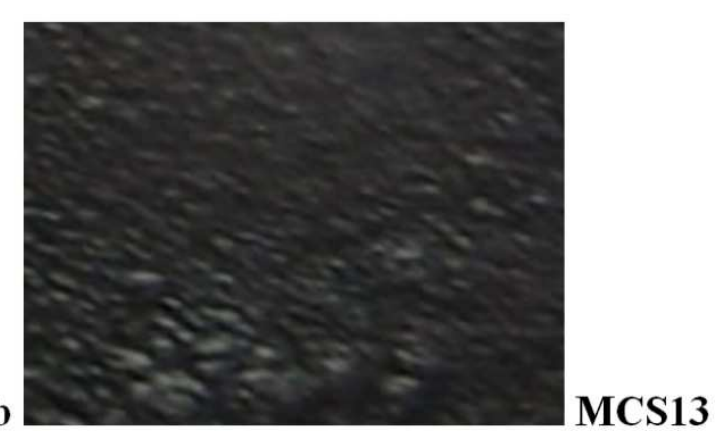

d

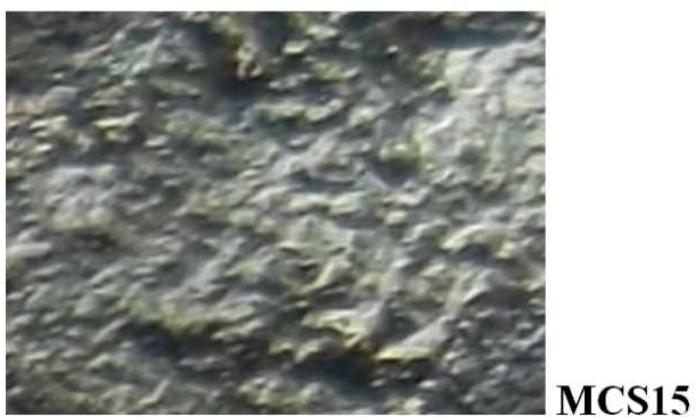

Fig. 4. EN plated, heat-treated MCS samples at (a) 150, (b) 210, (c) 250 and (d) $370{ }^{\circ} \mathrm{C}$ soaking temperatures (x50 mag.). 

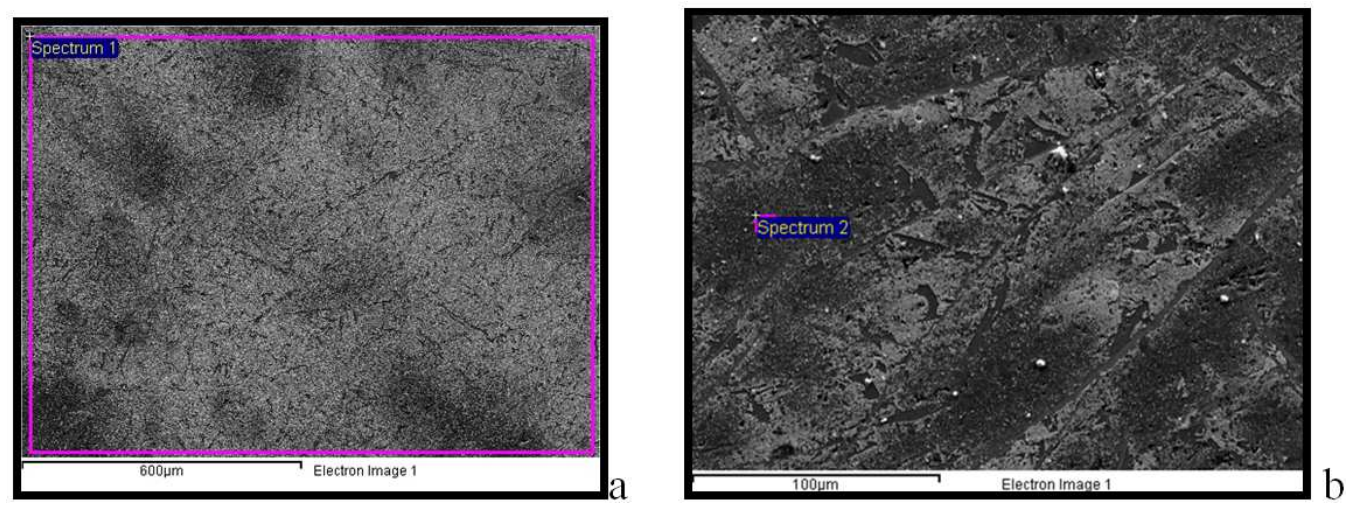

Fig. 5. SEM micrographs of (a) EN plating (x500 mag.) and (b) Ni-P rich portion on MCS (x1000 mag.).

\subsection{Effects of Heat Treatment on EN Film}

Figs. 6(a,b), 7 and Table 5 compare the SEM electron images of EN plating on MCS 11 (Fig 6 a,b) and the heat treated EN plating on MCS15 (Fig. 7). The observed portion of the heat treated EN deposition shows that the 100 um size of EN plating contains $10.39 \% \mathrm{P}$ and $61.07 \% \mathrm{Ni}$ as revealed in the EDX chemical characterisation data. The EDX data possibly shows that there was a little reduction in the $\% \mathrm{P}$ resulting from the hardening treatment held at $370{ }^{\circ} \mathrm{C}$ furnace temperature.

Table 5. EDX Spectrum processing data of EN plated chromate activated steel substrates (MCS11, MCS15)

\begin{tabular}{|c|c|c|c|c|c|c|c|c|c|c|c|}
\hline Element (Wt \%) & $\mathbf{C}$ & $\mathbf{O}$ & $\mathbf{N a}$ & $\mathbf{F e}$ & Si & Mn & $\mathrm{Cu}$ & $\mathbf{P}$ & $\mathrm{Cr}$ & $\mathbf{N i}$ & Total \\
\hline MCS 11 & 6.38 & 7.05 & 1.47 & 5.31 & 2.62 & 3.01 & 2.04 & 10.37 & 0.35 & 61.40 & 100 \\
\hline MCS 15 & 5.73 & 7.43 & 1.45 & 8.20 & 1.34 & 2.30 & 2.19 & 10.29 & 1.21 & 61.07 & 100 \\
\hline
\end{tabular}
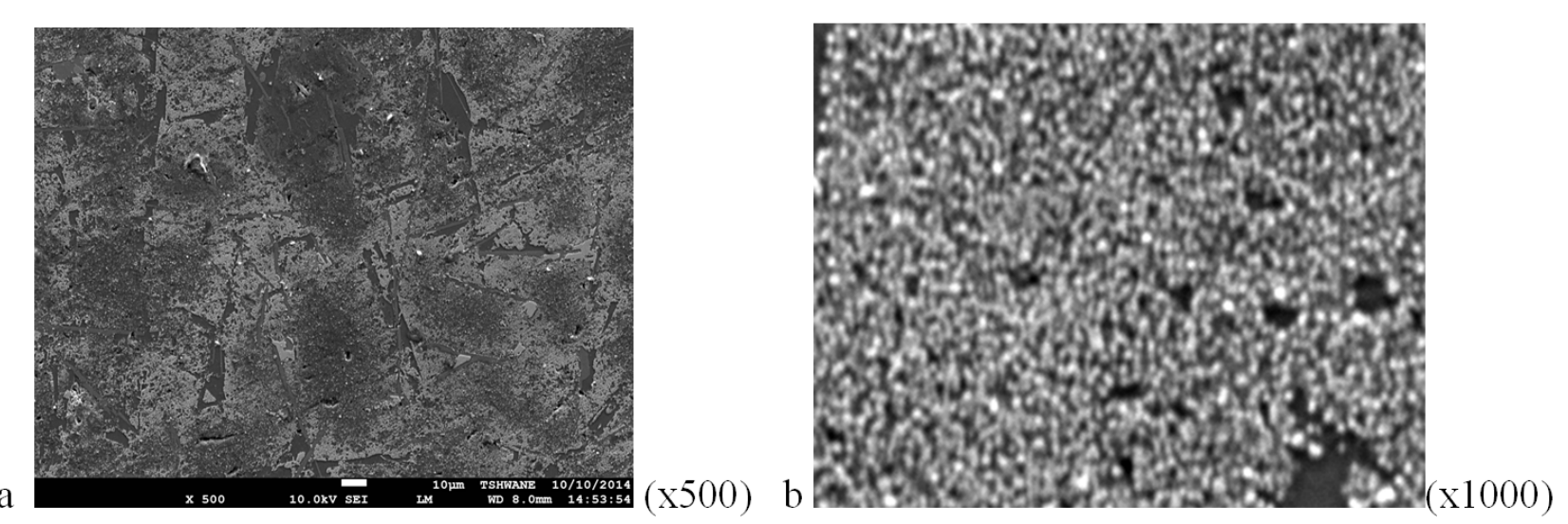

Fig. 6. SEM showing surfaces (a,b) of EN plated mild carbon steel (MCS11).

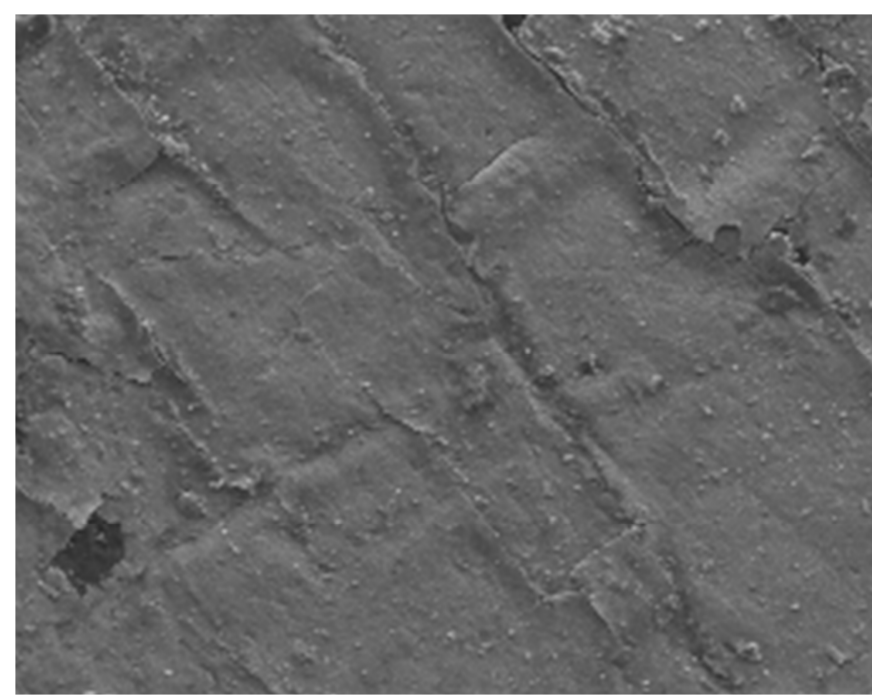

Fig. 7. SEM showing surface cracks on baked (MCS 15) heat treated EN film (x3000 mag.) 


\subsection{Corrosion Resistance Studies of Mild Carbon Steel Substrates}

The photo-macrographs of surfaces of the samples before and after immersion in the medium for 30 days are shown in
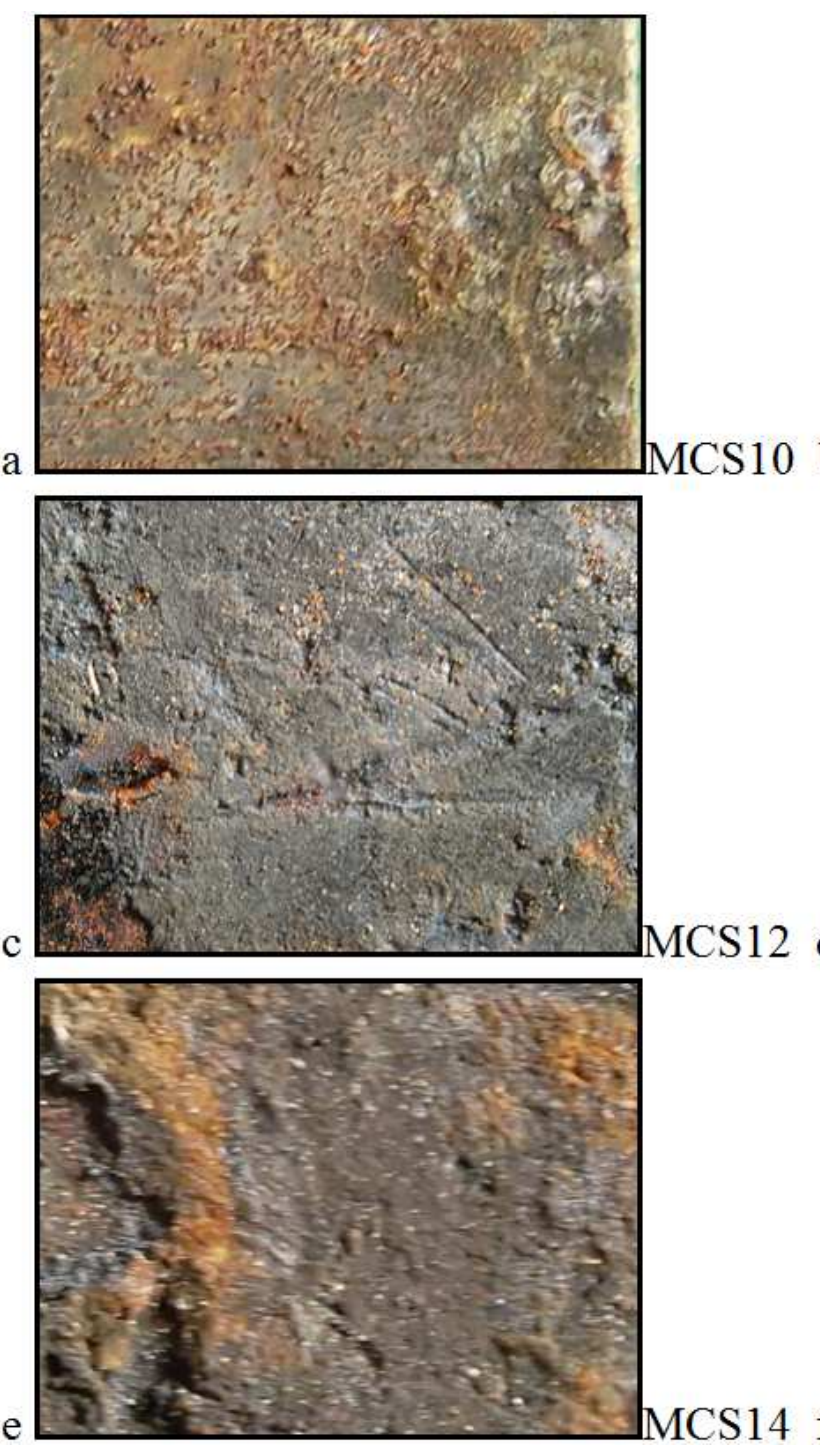

$\mathrm{MCS} 14 \mathrm{f}$
Figs. (8a) and (8b-f) respectively, while the results of corrosion rate determination of MCS substrate immersed in the medium by weight loss method are presented in Figs. 9-11.
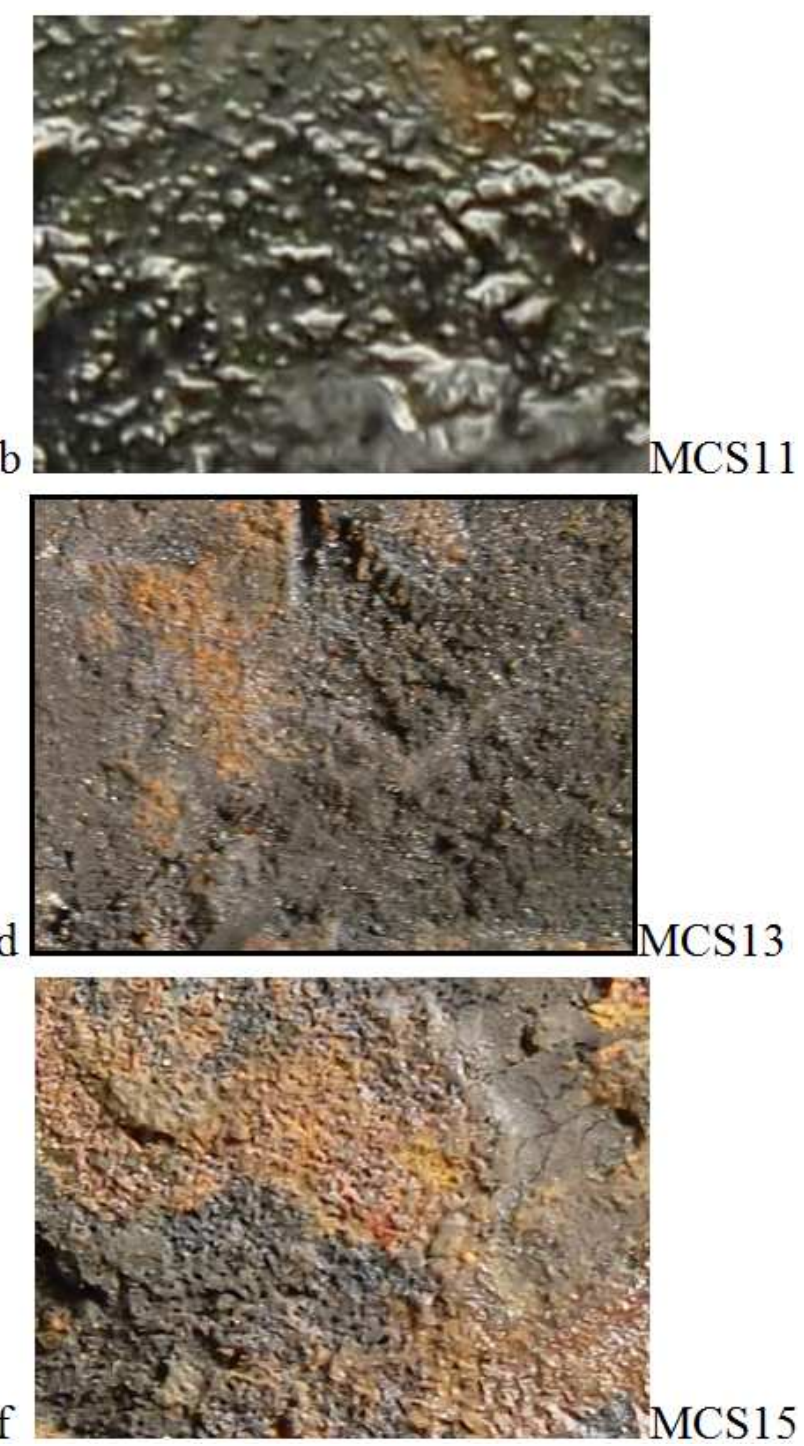

Fig. 8. Photomacrographs of the corroded EN plated MCS samples in $0.5 \mathrm{M} \mathrm{H}_{2} \mathrm{SO}_{4}(x 50 \mathrm{mag}$.).

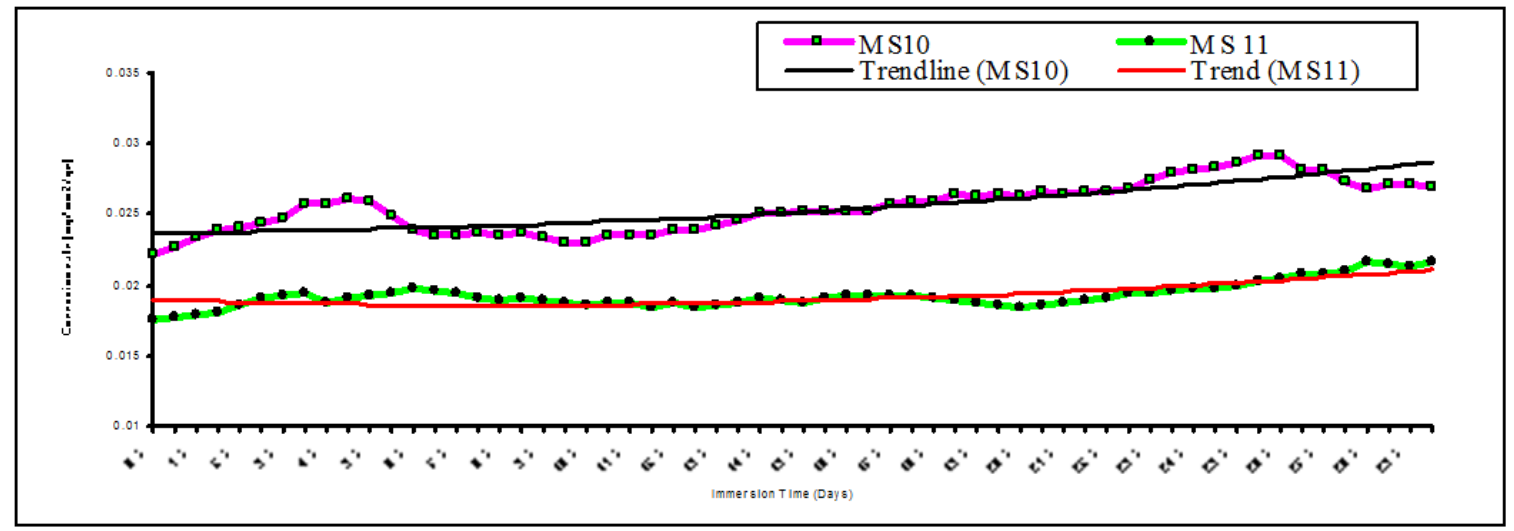

Fig. 9. Corrosion rates $\left(\mathrm{mg} / \mathrm{mm}^{2} / \mathrm{yr}\right)$ of MCS10 and MCS11 samples in $\mathrm{H}_{2} \mathrm{SO}_{4}$. 


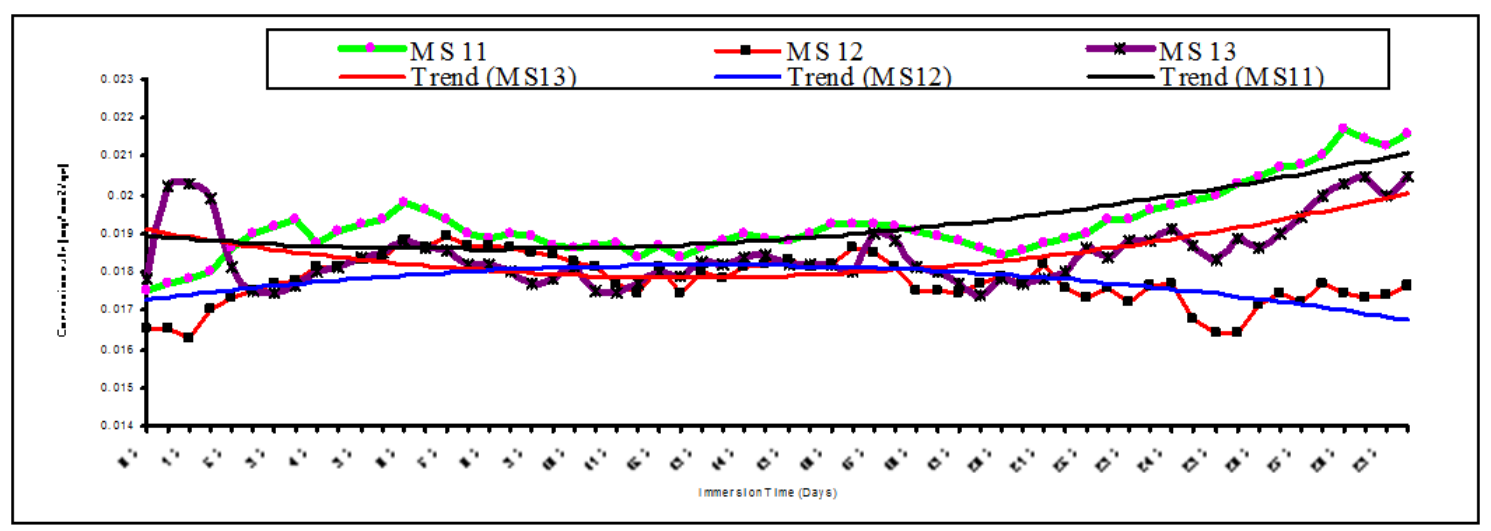

Fig. 10. Corrosion rates $\left(\mathrm{mg} / \mathrm{mm}^{2} / \mathrm{yr}\right)$ of MCS11, MCS12 and MCS13 samples in $\mathrm{H}_{2} \mathrm{SO}_{4}$.

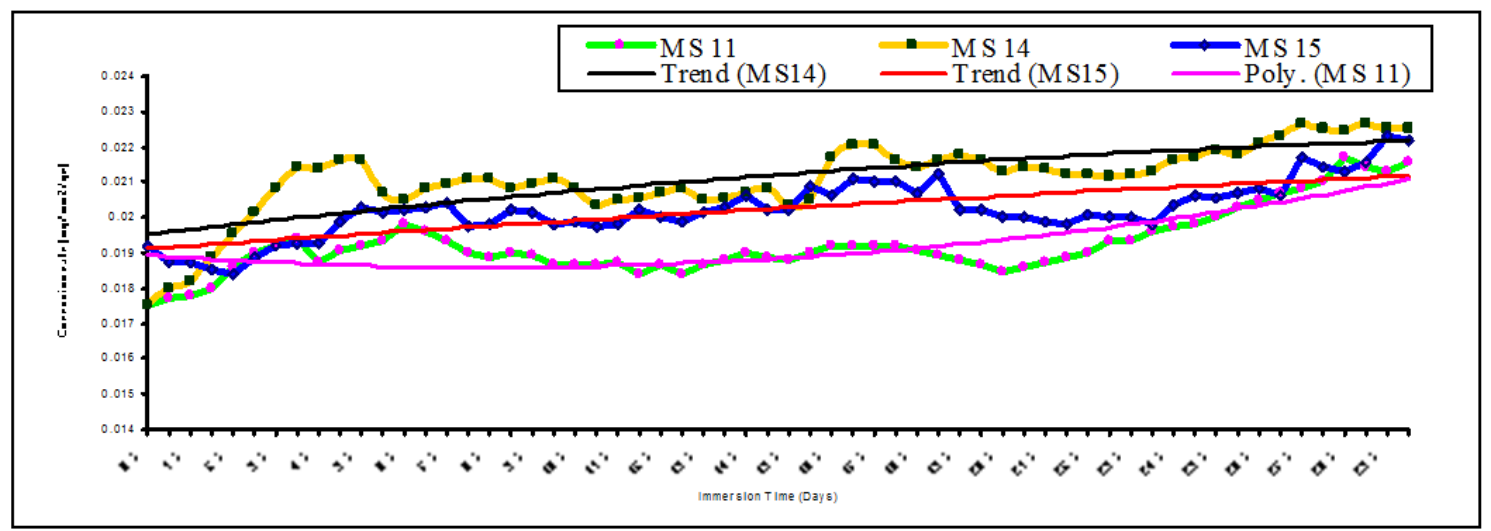

Fig. 11. Corrosion rates $\left(\mathrm{mg} / \mathrm{mm}^{2} / \mathrm{yr}\right)$ of MCS11, MCS14 and MCS15 samples in $\mathrm{H}_{2} \mathrm{SO}_{4}$.

Fig. 8a shows the photograph of the corroded surface of as received MCS samples (MCS-10) after 30 days of immersion. The corrosion is uniform over the surface. The white patches are the areas that were much affected. The corrosion rate was high for the 30 days of the observation.

Fig. 8b shows the macro-photograph of the corroded EN plated (MCS11) surface after 30 days immersion in the $0.5 \mathrm{M}$ $\mathrm{H}_{2} \mathrm{SO}_{4}$ solution. Though the corrosion was uniform over the surface, the EN coating makes it less severe in outlook than the corroded surface of the MCS samples. The debris of the surface attack was observed and became more noteworthy after 30 days. The corrosion rate curves of MCS10 (Fig. 8a) and MCS11 (Fig. 8b) samples are illustrated in Fig. 9.

Fig. 8c shows the surface layer of corrosion debris found or deposited on samples MCS12 after the immersion in the solution for 30 days as examined under microscopic camera.

Fig. 8d shows the photo macrograph of corrosion of the MCS13 sample surface after the immersion for 30 days with the waste product left on the samples surface. The colouration signifies the impact of the $\mathrm{Fe}$ ion on the corrosion of the base steel material in solution. The trends of the corrosion rates of MCS12 (Fig. 8c) and MCS13 samples (Fig. 8d) are shown in Fig. 10.

Fig. 8e shows the corrosion of MCS14 samples after 30 days with the layers of corrosion debris deposited on the sample surfaces. The brown patches colorations represent the areas of active corrosion at the interface of the electrolessnickel layer and the MCS substrate. The examined surface under the microscope also revealed the largest amount of pores in comparison to any of the MCS11, MCS12 and MCS13. This is due to the break in the film continuity and poor adhesion of the heat treated EN film to MCS substrate. A large amount of pores were observed on the surfaces after cleaning and examined under the microscope as compared with the MCS10 and MCS11 samples.

This thus allowed the access of the fluid to the MCS substrate surface and corrosion was accelerated.

In Fig. 8f, the surface of the MCS15 sample after the immersion in the medium is shown. The brownish portions show the much large corrosion affected areas as compared with other MCS11, MCS12 and MCS13 sample surfaces in $0.5 \mathrm{M} \mathrm{H}_{2} \mathrm{SO}_{4}$. The numerical trends of the corrosion rates of MCS14 (Fig. 8e) and MCS15 (Fig. 8f) samples are illustrated graphically in Fig. 11.

Using the results obtained in Figs. 9-11, the best fit models were developed for the trend using MS excel application of polynomial equations relating the corrosion rates of electroless-nickel in $0.5 \mathrm{M} \mathrm{H}_{2} \mathrm{SO}_{4}$. The mathematical model equations were derived for the corrosion rates as follow:

$$
\begin{aligned}
& \mathrm{R}_{M S 10}=1 \mathrm{E}-06 \mathrm{x}^{2}+1 \mathrm{E}-05 \mathrm{x}+0.0237 \\
& \mathrm{R}_{\mathrm{MS} 11}=1 \mathrm{E}-06 \mathrm{x}^{2}-5 \mathrm{E}-05 \mathrm{x}+0.0190 \\
& \mathrm{R}_{\mathrm{MS} 12}=-1 \mathrm{E}-06 \mathrm{x}^{2}+7 \mathrm{E}-05 \mathrm{x}+0.0172 \\
& \mathrm{R}_{\mathrm{MS} 13}=2 \mathrm{E}-06 \mathrm{x}^{2}-0.0001 \mathrm{x}+0.0192
\end{aligned}
$$




$$
\begin{aligned}
& R_{M S 14}=-4 E-07 x^{2}+7 E-05 x+0.0195 \\
& R_{M S 15}=-1 E-07 x^{2}+4 E-05 x+0.0191
\end{aligned}
$$

Where $0 \leq \mathrm{x} \leq 30, \mathrm{x}=$ immersion time (days), $\mathrm{R}_{\mathrm{MS} 10}, \mathrm{R}_{\mathrm{MS} 11}$, $\mathrm{R}_{\mathrm{MS} 12}, \mathrm{R}_{\mathrm{MS13}}, \mathrm{R}_{\mathrm{MS} 14}$ and $\mathrm{R}_{\mathrm{MS} 15}$ are the corrosion rates of the MCS10, MCS11, MCS12, MCS13, MCS14 and MCS15 with respect to immersion time in $0.5 \mathrm{M} \mathrm{H}_{2} \mathrm{SO}_{4}$ respectively.

Figs. 9-11 compares the corrosion rates $\left(\mathrm{mg} / \mathrm{mm}^{2} / \mathrm{yr}\right)$ of the MCS samples (MCS10), EN-plated MCS samples (MCS11) and the four heat treated EN-plated mild steel samples (MCS12, MCS13, MCS14, MCS15) in $0.5 \mathrm{M} \mathrm{H}_{2} \mathrm{SO}_{4}$. Objectively, the corrosion rate tests were performed to assess the level of surface degradation of the six substrates in $0.5 \mathrm{M} \mathrm{H}_{2} \mathrm{SO}_{4}$.

The effect of composition of EN coating on the corrosion resistant could be more appreciated from the EDX data obtained (Tables 3-5). The corrosion resistance of an EN coating is a function of its composition as revealed in the EDX data. The EN deposits are unsurprisingly passive (MCS11) and very resistant (MCS12 and MCS13) to corrosion attack as compared with the as-received sample (MCS10) in $0.5 \mathrm{M}$ $\mathrm{H}_{2} \mathrm{SO}_{4}$ environment. Their degree of passivity and corrosion resistance is greatly affected by the phosphorus content which also influenced the heat treated EN film products.

Predictably, the electroless Ni- $\mathrm{P}$ alloys with more than $10 \% \mathrm{P}$ is more resistant to the attack in $\mathrm{H}_{2} \mathrm{SO}_{4}$ environment. Frequently, the vagrant or some co-deposited constituents (such as lead, tin, cadmium, or sulphur) present in the EN play more important roles to its corrosion resistance than the phosphorus content.

One of the principal variables that can affect the corrosion of EN is its heat treatment as revealed in this study (MCS12 and MCS13). With the heat treated EN-plated MCS samples baked for 60 mins at 150 to $210{ }^{\circ} \mathrm{C}$; the $\mathrm{EN}$ film adhesion to the substrate is increased and by these treatments hydrogen is relieved from the substrate and the EN deposit [31]. The heat treatment provides a minor amount of co-diffusion between coating and substrate. Hence reduces the corrosion rates.

As nickel-phosphorus deposits are heated to temperatures above $220{ }^{\circ} \mathrm{C}$, nickel phosphide particles begin to form [31] instead the of the more corrosion resistant phosphate, hence reducing the phosphorus content of the remaining EN film material [11]. This reduces the corrosion resistance of the coating as shown in MCS14 and MCS15 samples immersed in the solution. In another case, the particles can also create small active corrosion cells, contributing to the additional destruction of the protective EN film deposit.

It has been reported that EN exposure to temperatures above $220{ }^{\circ} \mathrm{C}$ causes reduction in strength and this can destroy the ductility [11, 32, 33, 34, 35]. Usually, hardening type of heat treatments reduce both ductility and the strength of EN deposits, hence the coating breaks and resulted in high corrosion rate.

The contraction of the EN film resulting from the heat treatment (hardening) leads to crack formation on the coating that exposes the steel surface to corrosion attack. These are very much obvious the MCS14 and MCS15 corrosion as shown in Fig. 11. The EN heat treated at high temperature has tendency to crack under repetitive loads which implies a considerable reduction in the fatigue strength of steel substrates. The behaviour is different from the previous reports in the literature obtained from the EN plating of aluminium alloy [2-4, 26, 36-37] subjected to heat treatment [30] wear [19, 38-40] or corrosion [25, 41] or both [42]. The differences could be attributed to the EN plating bath parameters; mechanical properties, surface morphologies and the chemical compositions of the substrates [2-4, 20, 30, 4345]. Hence the EN baking at temperatures below $220{ }^{\circ} \mathrm{C}$ is encouraged by this study.

\section{Conclusion}

The collective effects of EN plating and heat treatment on the corrosion of the as-received mild carbon steel substrate, as EN-plated samples and the heat treated EN-film immersed in $0.5 \mathrm{M} \mathrm{H}_{2} \mathrm{SO}_{4}$ solution have been studied. From the results obtained, it will be right to select EN-plated samples (MCS11) and the low temperature heat treated EN-film (MCS12 and MCS13) for the reason of solving the problem of MCS corrosion in the medium. The application of EN plating enhanced the corrosion resistance of MCS at much lower rate than the heat treated heat treated EN-film (MCS14 and $\mathrm{MCS} 15)$ in $0.5 \mathrm{M} \mathrm{H}_{2} \mathrm{SO}_{4}$ environment.

\section{Acknowledgement}

The management of the Premier Wings Engineering Services, Ado Ekiti is hereby appreciated by the authors for the provision of the workshop services, the production and preparation of materials used for this study. Also the Head of the Electrochemical and Materials Characterization Research Laboratory of the Tshwane University of Technology, Pretoria, South Africa is acknowledged for all SEM analyses.

\section{References}

[1] Holmberg Kenneth, Ronkainen Helena, Laukkanen Anssi, Wallin Kim (2007). Friction and wear of coated surfaces scales, modelling and simulation of tribomechanisms, Surface \& Coatings Technology 202 (2007) 1034-1049.

[2] Ajibola O. O, Oloruntoba D. T and Adewuyi B. O (2014). Effect of hard surface grinding and activation on electrolessnickel plating on cast aluminium alloy substrates. Hindawi Publishing Corporation. Journal of Coatings. Volume 2014, $\begin{array}{llll}\text { Article ID } & 841619, & 10 & \text { pages. }\end{array}$ http://dx.doi.org/10.1155/2014/841619.

[3] Ajibola O. O and Oloruntoba D. T. (2014). Effects of polishing grades and Saccharin-550 additive on copper electroplating on NST60Mn and NST50-2 steels. International Journal of Innovation and Scientific Research, 8(2):334-344. http://www.ijisr.issr-journals.org/.

[4] Egunlae O. O and Adewuyi B. O (2008) Determination of plating parameter of steels in acid sulphate bath. J. Engineering and Earth Sciences, 3(1): 42-48. 
[5] Balaraju J N and Seshadri S K, (1999): "Preparation and characterization of electroless Ni-P and Ni-P-SiC composite coatings", Transaction of IMF, Vol 77, p84 in Pari et al, (2008): Study on the performance of electroless nickel coating on aluminium for cylinder liners. Patent F2008-SC-015, pp1.

[6] Kuzmik J. J, (1990): Plating on plastics, Chapter 14, Electroless plating. William Andrew Publishing/Noyes, pp 377-399. http://www.knovel.com.

[7] Anik M, Korpe E, Sen E (2008): Effect of coating bath composition on the properties of electroless nickel-boron films. Surf. Coat. Technol. 2008; 202(9):1718-1727.

[8] Agarwala R. C and Agarwala V (2003): Electroless alloy/composite coatings: A review. Sadhana 2003; 28(3-4): 475-493.

[9] Apachitei I, Tichelaar F D, Duszczyk J and Katgerman L. (2002): The effect of heat treatment on the structure and abrasive wear resistance of autocatalytic NiP and NiPSiC coatings, Surface Coating Technology, Vol. 149, p263. In Pari et al, (2008): Study on the performance of electroless nickel coating on aluminium for cylinder liners. Patent F2008-SC015 , pg 1.

[10] Palaniappa M, Seshadri SK. (2000): Friction and wear behaviours of electroless $\mathrm{Ni}-\mathrm{P}$ and $\mathrm{Ni}-\mathrm{W}-\mathrm{P}$ alloy coatings. Wear 2008; 265(5-6): 735-740.

[11] ASM Volume 5 (1994): Surface Engineering. The ASM Handbook. ASM International.

[12] Srinivasan KN, Meenakshi R, Santhi A, Thangavelu PR, John $\mathrm{S}$. Studies on development of electroless $\mathrm{Ni}-\mathrm{B}$ bath for corrosion resistance and wear resistance applications. Surf Eng. 2010; 26(3):153-8.

[13] Sankara Narayanan TSN, Baskaran I, Krishnaveni K, Parthiban S. Deposition of electroless Ni-P graded coatings and evaluation of their corrosion resistance. Surf. Coat. Technol. 2006; 200(11):3438-45.

[14] Das, Suman Kalyan and Sahoo Prasanta (2011): "Tribological characteristics of electroless $\mathrm{Ni}-\mathrm{B}$ coating and optimisation of coating parameters using Taguchi based grey relational analysis". Materials and Design 32 (2011) 2228-2238. ScienceDirect. www.elsevier.com/locate/matdes.

[15] Lee CK. Structure, electrochemical and wear-corrosion properties of electroless nickel-phosphorus deposition on CFRP composites. Mater. Chem. Phys. 2009; 114(1):125-33.

[16] Bayes, Dr. M. (1995). The Physical Properties of Electroless Nickel Coatings'. Proceedings EN 95 Conference, Cincinnati November 1995.

[17] Ye CY, Wang ZB, Yan ML, Li PQ. Resistance to $\mathrm{CO}_{2}$ corrosion of electroless plating of $\mathrm{Ni}$ - P coating on steel N80. Corros. Sci. Prot. Technol. 2005; 17(4):265.

[18] Lee MG, Yang TJ, Hsieh CA, Huang CC. Corrosion performance of electroless nickel-plated steel. In 19th (2009) International offshore and polar engineering conference, Osaka; 2009 June 21. p. 515-9.

[19] Ajibola O. O, Adewuyi B. O and Oloruntoba D. T (2014). Wear behaviour of sand cast eutectic Al-Si alloy in hydraulic brake fluid. International Journal of Innovation and Applied Studies, (IJIAS). 6 (3): 420-430. http://www.ijias.issrjournals.org/.
[20] Ajibola O. O, Oloruntoba D. T and Adewuyi B. O (2014). Metallurgical study of cast aluminium alloy used in hydraulic master brake calliper. International Journal of Innovation and Scientific Research (IJISR). 8(2):324-333. http://www.ijisr.issr-journals.org/.

[21] Arabani MR, Vaghefi SMM. Effect of heat-treatment on hardness and adhesion of Ni-P coated 7075 aluminum alloys by electroless deposition process. In: 15th IFHTSE International Federation for Heat Treatment and Surface Engineering Congress 2006, Vienna; 2006 September 25. p. 457-61.

[22] en.wikipedia.org/wiki/Electroless_nickel_plating.

[23] Bowden C, Matthews A. (1995) A study of the corrosion properties of PVD Zn-Ni coatings. Surface and Coatings Technology 76-77 (1995) 508-515.

[24] Adewuyi B. O (2002): The influence of $\mathrm{Fe}$ variation on the corrosion behaviour of heat treated aluminium alloys in tomato juice. Nigerian Journal of Technology, Vol. 21, No. 1, pp72-78.

[25] Adewuyi B. O and Egunlae O. O (2008) Corrosion characteristics of copper plated steels in active corrosive media. J. Engineering and Earth Sciences, 3(1): 29-35. ISSN$1897-8680$

[26] Egunlae O. O, Fasuba O. A, and Oloruntoba D. T. (2005) Influence of chlorides and organic additives on maintaining the brightening characteristics of copper electroplate on Nigerian low carbon NST50-2 Steel. Proceedings of 1st Engineering Forum Nov 7-10, 2005. 1(1): 49-53.

[27] Holmberg K., Matthews A., Coating Tribology: Principles, Techniques, and Application in Surface Engineering, Elsevier Science B. V., Amsterdam, 1994, p. 257.

[28] Endrino J. L., Fox-Rabinovich G. S., Gey C. (2006). Hard AlTiN, AlCrN PVD coatings for machining of austenitic stainless steel. Surface \& Coatings Technology 200 (2006) 6840-6845.

[29] Fontana M. G, (1986): Corrosion Engineering. (Third Edition) Mc Graw Hill Inc., New York. pp 4, 39-98, 294, 304-306.

[30] Oloruntoba D. T. (2009): Investigation of electrodeposition of nickel on heat treated low carbon steel substrate. FUTA. Thesis (Ph.D), 2009.

[31] Duncan R. N. (1982) Performance of Electroless Nickel Coatings in Oil Field Environments, CORROSION/82 Conference, National Association of Corrosion Engineers, March 1982.

[32] Gawrilov G. G. (1979) Chemical (Electroless) Nickel Plating, Portcullis Press, Redhill, England.

[33] Duncan R. N (1981) Properties and Applications of Electroless Nickel Deposits, Finish. Manage., 26 (3): 5.

[34] Stallman K. and Speckhardt H (1981), Deposition and Properties of Nickel-Boron Coatings, Metalloberfl.; Angew. Elektrochem., 35 (10): 979.

[35] Spahn H, (1964): The Effect of Internal Stress on the Fatigue and Corrosion Fatigue Properties of Electroplated and Chemically Plated Nickel Deposits, Proc. 6th Int. Metal Finish. Conf., Trans. Inst. Met. Finish., Vol 42, p 364. 
[36] Ajibola O. O, Oloruntoba D. T, and Adewuyi B. O, (2014): Effect of polishing grits, temperatures and selected activators on electroless-nickel deposition on cast aluminium substrates. Journal - The Institution of Engineers, Malaysia, Vol. 75, No. 2, Dec 2014: 43-51, (In Press).

[37] Ajibola O. O, Oloruntoba D. T, and Adewuyi B. O, (2015): Effect of Processing Parameters on the Protective Quality of Electroless-Ni on Cast Aluminium Alloy. Journal of Metallurgy, Volume 2015(2015), Article ID 386347, (In Press).

[38] Adewuyi B. O, Ajibola O. O, and Oloruntoba D. T, (2012): Design and performance evaluation of wear test jig for aluminium alloy substrate in hydraulic fluid". Proceedings of 8th Engineering Forum, Ado Ekiti, 23rd - 26th, October 2012, 8(1): 85-96.

[39] Ajibola O. O, Oloruntoba D. T, and Adewuyi B. O, (2014): Design and performance evaluation of wear test jig for aluminium alloy substrate in hydraulic fluid. A conference POSTER PRESENTATION, "AfriCORR 2014”, July 28-30, 2014, Pretoria, South Africa. https://www.researchgate.net/publication/264469855, DOI: $10.13140 / 2.1 .4363 .5844$.

[40] Ajibola O. O, Oloruntoba D. T, and Adewuyi B. O, (2015): Design and performance evaluation of wear test jig for aluminium alloy substrate in hydraulic fluid. African Corrosion Journal, Vol. 1 No. 1 April 2015. pp46-51.

[41] Ajibola O. O, Oloruntoba D. T, and Adewuyi B. O, (2015): Investigation of corrosion of cast aluminium alloy piston in brake fluid. African Corrosion Journal, Vol. 2, October, 2015. (In Press).

[42] Ajibola O. O and Oloruntoba D. T, (2015): Wear and Corrosion of cast $\mathrm{Al}$ alloy piston with and without brake oil. Indian Journal of Materials Science, Volume 2015(2015), Article ID 763618 (In Press).

[43] Ajibola O. O and Jimoh B. O, (2011): Aluminium recycling industries in Nigeria: Entrepreneurship challenges and opportunities. Proceedings of 7 th Engineering Forum, Ado Ekiti November 8 - 11, 2011, 7(2): 238-247.

[44] Ajibola O. O and Oloruntoba D. T, (2015): Effect of MgFeSi inoculant on properties of Cast 6061 Al Alloy for brake master piston application. Indian Journal of Materials Science Volume 2015(2015), Article ID 756219 (In Press).

[45] Ajibola O. O, Oloruntoba D. T, and Adewuyi B. O, (2015): Effects of moulding sand permeability and pouring temperatures on properties of cast 6061 Aluminium alloy. International Journal of Metals, Volume 2015(2015), Article ID 632021 (In Press). 